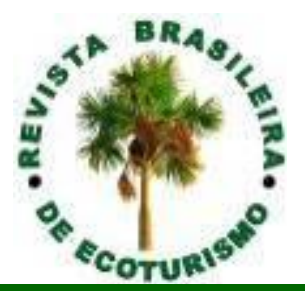

\title{
Panorama da interpretação ambiental e novas tecnologias: estudo de caso de Parques Nacionais Brasileiros da Região Sul
}

\section{Panorama of environmental interpretation and new technologies: A case study of Brazilian National Parks from southern Brazil}

\author{
Eduardo Henrique Dias Carvalho, Jasmine Cardozo Moreira, Leandro Baptista
}

\begin{abstract}
RESUMO: A aderência das pessoas a elementos tecnológicos cria oportunidades e a necessidade de aprimoramento de diversos setores. A interpretação ambiental em áreas naturais protegidas, cuja categoria Parque é o foco deste trabalho, é um conjunto de princípios e técnicas também passível de aprimoramento. O objetivo foi analisar o uso de novas tecnologias na interpretação ambiental de Parques Nacionais. A partir de um recorte geográfico que contemplou a região sul do Brasil, foram selecionados treze Parques Nacionais para a composição deste estudo. A metodologia utilizada foi a bibliográfica, a respeito de áreas naturais protegidas, interpretação ambiental e turismo e tecnologia, e a descritiva na organização dos resultados. Foi possível identificar os meios interpretativos atualmente utilizados nos Parques Nacionais brasileiros e modelos de meios interpretativos tecnológicos utilizados em outros países ao redor do mundo. Por fim, foi realizado um diagnóstico e propostas gerais e específicas para cada Parque.
\end{abstract}

PALAVRAS CHAVE: Interpretação Ambiental; Tecnologia; Parques Nacionais.

ABSTRACT: The propensity of people to use technological elements creates opportunities and the need to improve different sectors. The environmental interpretation in protected areas, mainly from the Park category, is a set of principles and techniques to improve the understanding of the areas. The goal of this paper was to analyze the use of new environmental interpretation technologies in 13 Brazil National Parks in the southern region of Brazil. The methodology used was developing a literature review related with protected areas, environmental interpretation, tourism and technology. The results were organized based on responses from the 13 National Parks managers. The study identified the technological interpretive resources currently used in Brazilian National Parks and models of technological interpretive resources used in other countries around the world. The conclusion include an in-depth analysis, and specific proposals were made for each park.

KEYWORDS: Environmental Interpretation; Technology; National Parks. 


\section{Introdução}

Este estudo considera os benefícios da utilização de ferramentas tecnológicas na interpretação ambiental de áreas naturais protegidas, sem que impactos negativos significativos sejam causados. Nos dias de hoje a adesão das pessoas a elementos tecnológicos cria oportunidades em diversos setores. O uso de meios interpretativos em áreas protegidas é uma maneira eficiente de sensibilizar os visitantes sobre a conservação ambiental, por meio da transmissão estratégica de informações.

A partir do uso de ferramentas como o $Q R$ Code, aplicativos, ferramentas audiovisuais, etc., em conjunto com as ferramentas tradicionais (painéis, panfletos, mapas, etc.), a interpretação ambiental pode se adequar mais facilmente ao estilo de vida das pessoas, assim como alcançar e sensibilizar novos públicos.

A tecnologia é capaz de auxiliar no processo de transmissão de informação de forma satisfatória se explorada adequadamente. De todo modo, é importante que o uso de tecnologias não descaracterize os locais, para que as gerações futuras possam conhecer suas características (VALE; ROBLES; MOREIRA, 2016). No Brasil, entretanto, ainda existe baixa incidência no uso de novas tecnologias, se comparado com áreas protegidas norte americanas, europeias ou de outros parques ao redor do mundo.

Para possibilitar a criação de propostas específicas e direcionadas, portanto, foi realizado um recorte geográfico contemplando Unidades de Conservação (UCs) nacionais da categoria Parque, limitando-se à região sul do Brasil, sendo ao todo, treze Parques Nacionais.

Com base no cenário descrito, o objetivo deste estudo foi analisar o uso de ferramentas tecnológicas como meios interpretativos nessas UCs da categoria Parque. A metodologia englobou a identificação de novas tecnologias que estão sendo utilizadas na interpretação ambiental de outros países e nos Parques Nacionais do sul do Brasil, e a realização de diagnóstico com relação a utilização atual de ferramentas tecnológicas nos Parques Nacionais do sul do Brasil. Por fim, é feita a proposta de implementação desses meios interpretativos tecnológicos.

Foi feita pesquisa bibliográfica, que forneceu o embasamento necessário para compreender: as áreas naturais protegidas, em especial Parques Nacionais; aspectos relacionados à interpretação ambiental e ao uso de meios interpretativos tecnológicos e tradicionais; e o uso de novas tecnologias no turismo de modo geral. Também foi feita pesquisa descritiva, para a realização de levantamentos de informações, os diagnósticos e as propostas.

$\mathrm{Na}$ tabulação dos meios interpretativos utilizados atualmente nos Parques Nacionais foram utilizados dados do questionário aplicado por Baptista (2019), e respondido pelos próprios gestores dos Parques. Os questionários foram enviados por e-mail. Dos treze Parques Nacionais da região sul, não se obteve respostas de apenas dois, onde foram coletadas informações secundárias no site do ICMBio Instituto Chico Mendes de Conservação da Biodiversidade (2020). Para identificar e apresentar os exemplos de meios interpretativos tecnológicos utilizados em outros países foram utilizados dados bibliográficos e de lojas e sites de aplicativos. 


\section{Área de Estudo: Os Parques Nacionais da Região Sul do Brasil}

Uma área natural protegida é um espaço geográfico claramente definido e gerido através de meios legais ou outros meios efetivos para alcançar a conservação a longo prazo da natureza, em conjunto com valores culturais (IUCN, 2008). O Ministério do Meio Ambiente (MMA, 2016) complementa este conceito ao dizer que são áreas de terra e/ou mar dedicadas à proteção e manutenção da diversidade biológica e de seus recursos naturais e culturais, reafirmando que podem ser manejadas por meio de instrumentos legais ou outros meios efetivos.

No Brasil, as áreas naturais protegidas com o propósito de proteger elementos da biodiversidade e geodiversidade, as paisagens e ecossistemas, são chamadas de Unidades de Conservação (UCs). O Sistema Nacional de Unidades de Conservação (SNUC), na Lei de ํㅜ 9.985 de 2000, art. 2º , define as UCs como:

Espaços territoriais e seus recursos ambientais, incluindo as águas jurisdicionais, com características naturais relevantes, legalmente instituídos pelo Poder Público, com objetivos de conservação e limites definidos, sob regime especial de administração, ao qual se aplicam garantias adequadas de proteção (BRASIL, 2000).

As UCs são instituídas e geridas pelo poder público federal, estadual ou municipal, e são divididas em dois grupos com características específicas: as Unidades de Uso Sustentável, que compatibilizam a conservação da natureza com o uso sustentável de parcela dos seus recursos naturais; e as Unidades de Proteção Integral, em que se admite apenas o uso indireto dos seus recursos naturais.

Os Parques Nacionais se enquadram nesta segunda categoria. Segundo Rocha et al. (2010), a criação e a gestão das UCs federais foram dissociadas das funções do lbama e repassadas ao Instituto Chico Mendes de Conservação da Biodiversidade (ICMBio), em 2007, por meio da Lei n. 11.516, de 28 de agosto de 2007.

O SNUC (Lei o 9.985/2000, Art. 11) apresenta como objetivo básico dos Parques Nacionais a preservação de ecossistemas naturais de grande relevância ecológica e beleza cênica, afirmando que é possível realizar pesquisas científicas e desenvolver atividades de educação e interpretação ambiental, de recreação em contato com a natureza e de turismo ecológico nestes locais.

A região sul do Brasil é composta pelos estados do Paraná, Rio Grande do Sul e Santa Catarina, e possui 13 Parques Nacionais. Essas UCs estão situadas predominantemente em territórios do bioma Mata Atlântica e são apresentadas a seguir, em ordem cronológica de criação.

O Parque Nacional do Iguaçu, criado em 1939 e localizado no estado do Paraná, faz parte do bioma mata atlântica e abriga o maior remanescente de floresta atlântica da região sul do Brasil. Protege riquíssima biodiversidade constituída por espécies representativas da fauna e flora brasileira, incluindo espécies em extinção (ICMBIO, 2017a). 
O Parque Nacional de Aparados da Serra, criado em 1959 e localizado no estado do Rio Grande do Sul, faz parte do bioma mata atlântica e está situado em região de relevo bastante peculiar, caracterizado principalmente por desfiladeiros com paredões verticais de até 700 metros de altura (ICMBIO, 2017b).

O Parque Nacional de São Joaquim, criado em 1961 e localizado no estado de Santa Catarina, mais especificamente na região serrana do estado, faz parte do bioma mata atlântica e existe em função da necessidade de proteção dos remanescentes de matas araucárias, somando-se à relevância das terras, flora, fauna e belezas naturais (ICMBIO, 2017c).

O Parque Nacional da Lagoa do Peixe, criado em 1986 e localizado no Rio Grande do Sul, faz parte do bioma marinho costeiro e protege espécies ameaçadas como o gavião-cinza, a gaivota-de-rabo-preto, a sanã-cinza e o trinta-réis-real (ICMBIO, 2017d).

O Parque Nacional do Superagui, criado em 1989 e localizado no Paraná, faz parte do bioma mata atlântica e está situado em área reconhecida como sítio do Patrimônio Natural (UNESCO), Reserva da Biosfera e Patrimônio Natural e Histórico do Paraná. Abrange territórios insulares e continentais com espécies ameaçadas e endêmicas (ICMBIO, 2017e).

O Parque Nacional da Serra Geral, criado em 1992 e localizado na porção mais oriental da divisa dos estados do Rio Grande do Sul e Santa Catarina, faz parte do bioma mata atlântica e se destaca pela conformação geográfica peculiar, caracterizada principalmente por paredões verticais de até 700 metros de altura, assim como em Aparados da Serra (ICMBIO, 2017f).

O Parque Nacional de Ilha Grande, criado em 1997 e localizado no Paraná, na divisa com o estado do Mato Grosso do Sul (MS), faz parte do bioma mata atlântica e se situa em região caracterizada pela existência de sítios arqueológicos de excepcional relevância para a compreensão da ocupação humana no sul do continente americano, com cenário dominado por lagos, lagoas, várzea continental e cerca de 180 ilhas e ilhotas (ICMBIO, 2017g).

O Parque Nacional de Saint Hilaire-Lange, criado em 2001 e localizado no Paraná, está situado no bioma mata atlântica e protege diversas espécies ameaçadas, entre elas o papagaio-da-cara-roxa, a maria-da-restinga, a onça-parda, o bicudinho-do-brejo e a socó-jararaca (ICMBIO, 2017h).

O Parque Nacional da Serra do Itajaí, criado em 2004 e localizado em Santa Catarina, protege aproximadamente 57 mil hectares de florestas, em sua maioria em avançado estágio de regeneração, preservando a maior área contínua de mata atlântica do estado (ICMBIO, 2017i).

O Parque Nacional das Araucárias, criado em 2005 e localizado em Santa Catarina, faz parte do bioma mata atlântica e protege espécies ameaçadas como o lobo-guará, o pica-pau-de-cara-amarela, o gato-maracajá e a onça-parda (ICMBIO, 2017j).

O Parque Nacional dos Campos Gerais, criado em 2006 e localizado na região dos Campos Gerais do Paraná, faz parte do bioma mata atlântica e possui área de 21.298,91 hectares (ICMBIO, 2017k). 
O Parque Nacional Marinho das Ilhas dos Currais, criado em 2013 e localizado no Paraná, se situa em bioma marinho costeiro e possui $1.359,70$ hectares de área (ICMBIO, 2017I).

E, por fim, o Parque Nacional de Guaricana, criado em 2014 e localizado no Paraná, abrange cerca de 49.000 hectares de mata atlântica no litoral e na Serra do Mar paranaense (ICMBIO, 2017m).

Todos os Parques Nacionais da região sul do Brasil (Figura 1) apresentam potencial turístico e de educação ambiental. A atividade turística, entretanto, deve ser realizada de maneira sustentável, visando conservar os recursos naturais que possuem, considerados seu maior atrativo.

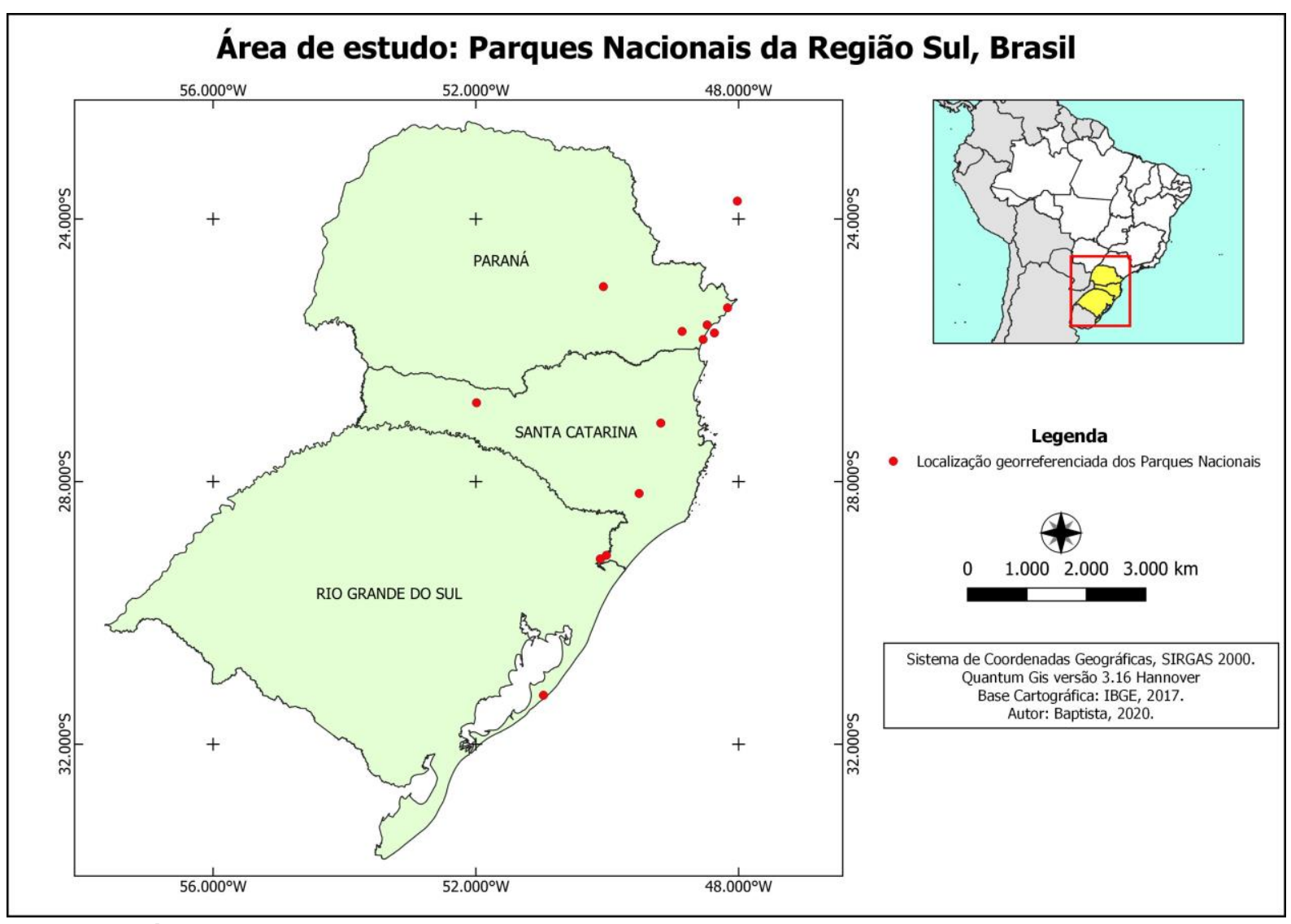

Figura 1: Mapa de Localização dos Parques Nacionais destacados neste estudo.

Figure 1: National Parks Location Map highlighted in this study.

Fonte: Elaborado por Baptista (2020).

Source: Elaborated by Baptista (2020).

\section{Aspectos da interpretação ambiental e os meios interpretativos que utilizam novas tecnologias}

Um dos principais elementos da atividade turística é a informação. Os turistas (e visitantes), precisam de informações sobre o destino, as operadoras precisam de informações para montar pacotes adequados e os gestores de empreendimentos precisam de informações para melhor atender os turistas, utilizar melhor os seus recursos, e assim por diante. Para isso são necessários sistemas que realizam o recolhimento e a organização de informações, através de fontes 
internas e externas, que auxiliam os gestores no planejamento e nas tomadas de decisão. Tais sistemas, também chamados de tecnologias de informação e comunicação (TICs), estão avançando a cada dia e apresentam vantagens competitivas, estratégicas e com potencial visão de futuro (RAMOS et al., 2009).

É possível ir adiante, considerando a utilização das TICs como um meio de sensibilizar e educar os visitantes de um destino. De acordo com Candello (2012), os moradores e visitantes são os principais agentes que estimulam a atividade turística por meio das TICs, através de sites informativos, blogs/microblogs e aplicativos com conteúdo gerado pelos próprios usuários.

Ao observar que as novas gerações, em sua maioria, não consideram um mundo sem celular ou internet, e a partir da aderência de elementos tecnológicos por parte das populações em geral, Rocha et al., (2015) discutem sobre o desinteresse no processo de aprendizagem em função da ausência de tecnologias no ambiente de aprendizado, no entanto, afirmam que não se trata somente de uma questão de promoção de acesso aos recursos tecnológicos, mas também de avaliar e saber como empregar tais recursos nas práticas educativas.

Deve haver ponderação entre aquilo que a tecnologia propicia e a consequente degradação do meio ambiente (BENHOSSI; FACHIN, 2013). Neste cenário, nota-se a importância da implementação consciente da tecnologia na interpretação ambiental, no sentido de maximizar seus benefícios, seja através do aumento no alcance das informações e da adesão de novos públicos, como também em função da maior efetividade no processo de aprendizado.

Para Andrade (2004), a necessidade de incorporar com maior ênfase a perspectiva de inovação na discussão ambiental vem se consolidando recentemente. A inovação requer um rearranjo cultural, institucional e organizacional que discuta as condições de armazenamento de recursos, intercâmbios de componentes e gestão de sistemas integrados de informação em padrões complexos e ao mesmo tempo transparentes. Porém, enquanto a inovação manterse redundante e focada na produção e no desenvolvimento contínuo, permitindo o desperdício de recursos, as perspectivas de sustentabilidade são prejudicadas.

A preocupação com o meio ambiente caminha ao lado de toda a expectativa por novidades tecnológicas, ambas as situações estarão sempre juntas, não se admitindo a prevalência de uma em detrimento da outra (BENHOSSI; FACHIN, 2013).

Já a interpretação, de maneira ampla, refere-se a atividades educativas realizadas em lugares como jardins zoológicos, museus, patrimônios históricos ou culturais e parques nacionais, para mostrar aos visitantes a importância ou o significado das experiências vividas nestes locais (MOSCARDO et al., 2005). Ham (1992) define a interpretação ambiental como uma forma de interpretação utilizada explicitamente para propósitos ambientais e de conservação, traduzindo a linguagem técnica de uma ciência natural em ideias que as pessoas em geral consigam entender.

As mensagens interpretativas devem ser atraentes a ponto de chamar a atenção, devem ter significado para que as pessoas se importem, e devem ser 
interessantes o suficiente para que as pessoas não pensem ou ajam da mesma forma após as terem visto (BECK; CABLE, 2011).

A interpretação ambiental efetiva traz inúmeros benefícios para o local, em termos de valorização e conservação, bem como benefícios sociais e para a experiência dos visitantes, tornando-se uma importante ferramenta de gestão.

Forist et al., (2003) apresentam exemplos de meios interpretativos, tais como: folhetos e mapas; centros de visitantes, museus, exposições e centros de exibições naturais; exposições de beira de estrada e trilhas autoguiadas; elementos audiovisuais, apresentações de slides, vídeos, programas interativos e filmes; jornais, boletins informativos e cronogramas de atividades; páginas na internet e estações de rádio; apresentações em auditórios, narrações e programas em barcos e trilhas, e outros. Esses exemplos podem ser considerados como meios interpretativos tradicionais.

Os meios tecnológicos são aqueles que se apropriam de novas tecnologias para a transmissão de informações, através do uso de GPS, códigos $Q R$, aplicativos para smartphones, tecnologia 3D e de realidade aumentada, bem como outros tipos de softwares interativos. Kirner e Zorzal (2005) definem a realidade aumentada como uma mistura de um cenário real com objetos virtuais gerados por computador, produzindo um único ambiente sobreposto ao ambiente físico.

Tais ferramentas possibilitam novas abordagens, com diferentes estímulos e menos limitações. $O$ uso de elementos audiovisuais e de plataformas virtuais pode não ser considerado novidade, mas as possibilidades de utilização dessas ferramentas estão se tornando cada vez mais amplas em função do constante aprimoramento tecnológico.

Alguns empreendimentos privados próximos à Parques Nacionais norteamericanos como o Grand Canyon e o Yellowstone vêm utilizando a tecnologia IMAX em filmes de alta resolução, explicando um pouco sobre a geologia e geomorfologia local. Na Espanha, a tecnologia 3D é encontrada em parques temáticos como o Dinópolis, retratando desde o Big Bang até a Era dos Dinossauros. Em um Geopark de Hong Kong, foi desenvolvida uma espécie caneta falante que funciona através da leitura de códigos de barras em vários idiomas, reproduzindo informações de aspectos geológicos do local (MOREIRA, 2014). Esse e outros exemplos estão descritos no Quadro 1 (próxima página).

Moreira (2014, p. 80) também afirma que "deve-se conhecer o tipo de público a que se destina a interpretação para então definir-se a mensagem e escolher os meios interpretativos mais convenientes aos visitantes". No Brasil, exemplos de novidades tecnológicas na interpretação ambiental de Parques Nacionais ainda são raros.

Os aplicativos, ou APPs, disponíveis principalmente nas plataformas "Google Play", e na "Apple Store", da Apple Inc., são executados em vários dispositivos, dentre eles, os smartphones. Atualmente os smartphones são os dispositivos móveis de uso mais comum. 
Quadro 1: Meios interpretativos tecnológicos em outros países.

Frame 1: Technological interpretive media in other countries.

\begin{tabular}{|c|c|c|}
\hline $\begin{array}{c}\text { Meio } \\
\text { Interpretativo }\end{array}$ & Localização & Descrição \\
\hline \multirow[t]{2}{*}{$\begin{array}{l}\text { Sala de cinema } \\
\text { com tecnologia } \\
\text { IMAX. }\end{array}$} & $\begin{array}{l}\text { Parque Nacional do } \\
\text { Grand Canyon - } \\
\text { Estados Unidos. }\end{array}$ & $\begin{array}{l}\text { Uma tela de cinema de seis andares e mais de } 12.000 \\
\text { watts de som surround digital permitem que os visitantes } \\
\text { experimentem a história do Grand Canyon ao longo do } \\
\text { tempo, além de um passeio de rafting pelo rio Colorado } \\
\text { enquanto estão sentados e confortáveis (NATIONAL } \\
\text { GEOGRAPHIC, 2018a). }\end{array}$ \\
\hline & $\begin{array}{l}\text { Parque Nacional de } \\
\text { Yellowstone - } \\
\text { Estados Unidos. }\end{array}$ & $\begin{array}{l}\text { É apresentado um filme com a história de Yellowstone até } \\
\text { os dias atuais, contribuindo com a experiência dos } \\
\text { visitantes ao visitarem o Parque posteriormente (TRIP } \\
\text { ADVISOR, 2018a). }\end{array}$ \\
\hline $\begin{array}{l}\text { Apresentações } \\
\text { audiovisuais; } \\
\text { Atividades } \\
\text { recreativas com } \\
\text { tecnologia 3D; } \\
\text { Jogos } \\
\text { eletrônicos; } \\
\text { Cinema virtual. }\end{array}$ & $\begin{array}{l}\text { Parque Temático de } \\
\text { Dinópolis - Espanha. }\end{array}$ & $\begin{array}{l}\text { A tecnologia 3D, em formato de filmes, jogos e } \\
\text { hologramas, possibilita atividades que retratam desde o } \\
\text { Big Bang até a Era dos dinossauros, recriam os próprios } \\
\text { dinossauros e algumas áreas arqueológicas de } \\
\text { escavações (SONO, 2018). }\end{array}$ \\
\hline $\begin{array}{l}\text { Guia por } \\
\text { Nintendo 3DS; } \\
\text { Jogo eletrônico. }\end{array}$ & $\begin{array}{l}\text { Museu do Louvre - } \\
\text { França. }\end{array}$ & $\begin{array}{l}\text { É um software desenvolvido para viver a experiência do } \\
\text { museu, através de guias de áudio, no conforto de casa. O } \\
\text { software pode ser utilizado de várias maneiras, simulando } \\
\text { uma rota pelo museu antes de visitá-lo ou simplesmente } \\
\text { usando-o como ponto de partida para o desenvolvimento } \\
\text { de uma maior apreciação pela arte (NINTENDO, 2018). }\end{array}$ \\
\hline $\begin{array}{l}\text { Caneta } \\
\text { Interpretativa } \\
\text { Falante. }\end{array}$ & $\begin{array}{l}\text { Geopark de Hong } \\
\text { Kong - China. }\end{array}$ & $\begin{array}{l}\text { O visitante compra um mapa que possui códigos de } \\
\text { barras nos principais pontos que podem ser interpretados } \\
\text { e aluga a caneta no Centro de Visitantes. A caneta } \\
\text { reproduz informações geológicas gravadas quando sua } \\
\text { ponta encosta em um dos códigos de barras. É possível } \\
\text { escolher entre os idiomas cantonês, mandarim, inglês ou } \\
\text { japonês (NG; FUNG; NEWSOME, } 2010 \text { apud MOREIRA } \\
\text { 2014). }\end{array}$ \\
\hline Tour com GPS. & $\begin{array}{l}\text { Parque Nacional Banff } \\
\text { - Canadá. }\end{array}$ & $\begin{array}{l}\text { O visitante tem a oportunidade de passear com seu } \\
\text { próprio carro enquanto recebe informações através de } \\
\text { recursos de áudio ao passar por determinados pontos do } \\
\text { Parque, agregando um elemento educacional e mais valor } \\
\text { à visita (TRIP ADVISOR, 2018b). }\end{array}$ \\
\hline
\end{tabular}

Fonte: Elaborado pelos autores (2020), baseado em Moreira (2014).

Source: Elaborated by the authors (2020), based on Moreira (2014).

Existem desde aplicativos com funções e visual simplificados até aqueles que incorporam tecnologias recentes como a tecnologia tridimensional (3D) ou de realidade aumentada, trazendo novas possibilidades de aplicabilidade.

O Quadro 2 é constituído de exemplos de aplicativos que estão sendo utilizados em alguns lugares do mundo. Estes encontram-se dispostos juntamente com uma descrição que busca contemplar suas características principais, bem como seus principais pontos positivos. Tratam-se de ferramentas que possibilitam novas abordagens de interpretação, e que mediante algumas adaptações, podem ser incorporadas na interpretação ambiental das UCs brasileiras. 
Quadro 2: Meios interpretativos tecnológicos em outros países - Aplicativos.

Frame 2: Technological interpretive media in other countries - Apps.

\begin{tabular}{|c|c|c|}
\hline $\begin{array}{c}\text { Meio } \\
\text { Interpretativo }\end{array}$ & Localização & Descrição \\
\hline $\begin{array}{l}\text { Aplicativo sobre } \\
\text { Parques Nacionais } \\
\text { Americanos. }\end{array}$ & $\begin{array}{l}\text { Parques Nacionais } \\
\text { Americanos - } \\
\text { Estados Unidos. }\end{array}$ & $\begin{array}{l}\text { Possui guias para os parques mais visitados dos } \\
\text { Estados Unidos. Para cada Parque, o aplicativo fornece } \\
\text { informações gerais, guias de viagens, contatos, } \\
\text { informações para entrada, as regras dos Parques, } \\
\text { tweets recentes, informações atualizadas sobre o clima } \\
\text { e avisos especiais. Além disso, possui fotos de cada } \\
\text { Parque, mapas detalhados e filtros para organizar todos } \\
\text { estes recursos (NATIONAL GEOGRAPHIC, 2018b). }\end{array}$ \\
\hline $\begin{array}{l}\text { Aplicativos sobre a } \\
\text { vida selvagem nos } \\
\text { Parques Nacionais } \\
\text { Americanos. }\end{array}$ & $\begin{array}{l}\text { Parques Nacionais } \\
\text { Americanos - } \\
\text { Estados Unidos. }\end{array}$ & $\begin{array}{l}\text { Trata-se de um guia de campo que ajuda os visitantes a } \\
\text { identificarem animais selvagens e plantas nos Parques } \\
\text { Nacionais dos Estados Unidos, fornecendo informações } \\
\text { sobre cada espécie (GOOGLEPLAY, 2018a). }\end{array}$ \\
\hline $\begin{array}{l}\text { Aplicativo oficial } \\
\text { dos Jardins de } \\
\text { Kew. }\end{array}$ & $\begin{array}{l}\text { Jardins Botânicos } \\
\text { Reais de Kew - } \\
\text { Reino Unido. }\end{array}$ & $\begin{array}{l}\text { O aplicativo ajuda o visitante a explorar melhor os } \\
\text { jardins e seus aspectos científicos e de horticultura. As } \\
\text { informações, como textos, vídeos e imagens, são } \\
\text { acessadas com o uso de códigos QR (STRATEGIC } \\
\text { CONTENT, 2018). }\end{array}$ \\
\hline $\begin{array}{l}\text { Aplicativo } \\
\text { Leafsnap. }\end{array}$ & $\begin{array}{l}\text { Estados Unidos e } \\
\text { Canada. }\end{array}$ & $\begin{array}{l}\text { Ajuda as pessoas a identificarem espécies de árvores a } \\
\text { partir da fotografia de suas folhas, utilizando software } \\
\text { de reconhecimento visual. Atualmente inclui árvores } \\
\text { encontradas no nordeste dos Estados Unidos e no } \\
\text { Canadá (APPLE STORE, 2018). }\end{array}$ \\
\hline $\begin{array}{l}\text { Aplicativo Coral } \\
\text { RKV (Rekindling } \\
\text { Venus Coral). }\end{array}$ & $\begin{array}{l}\text { Recifes de corais ao } \\
\text { redor do mundo. }\end{array}$ & $\begin{array}{l}\text { Trata-se de um aplicativo artístico de realidade } \\
\text { aumentada que trabalha com cartazes que criam um } \\
\text { "portal" para os recifes de corais do mundo. Ele pode } \\
\text { ser usado onde quer que existam pôsteres RKV, } \\
\text { escaneando as imagens para assistir ao ambiente de } \\
\text { recifes 3D ganhando vida (GOOGLE PLAY, 2018b). }\end{array}$ \\
\hline Aplicativo Zoo-AR & $\begin{array}{l}\text { Zoológicos e } \\
\text { aquários ao redor do } \\
\text { mundo. }\end{array}$ & $\begin{array}{l}\text { Com o intuito de aprimorar as mensagens educativas e } \\
\text { educacionais, o aplicativo utiliza da realidade } \\
\text { aumentada para disponibilizar a visualização em 3D de } \\
\text { uma variedade de animais e insetos, a fim de despertar } \\
\text { o interesse do visitante na conservação destas } \\
\text { espécies. (ZOO-AR, 2018). }\end{array}$ \\
\hline
\end{tabular}

Fonte: Elaborado pelos autores (2020).

Source: Elaborated by the authors (2020).

A tecnologia 3D e a realidade aumentada são elementos visualmente atraentes com diversas possibilidades de utilização. Os aplicativos, por sua vez, possibilitam desde a criação de gigantescos bancos de dados até a formatação de softwares interativos e que podem ser utilizados por qualquer indivíduo. Tais recursos vêm sendo incorporados, em diferentes níveis, à interpretação ambiental de UCs em outros países, com índices satisfatórios de efetividade em especial para os modelos dispostos anteriormente.

Os Parques Nacionais americanos podem servir como exemplo para os Parques brasileiros na utilização das vantagens da tecnologia móvel, seja no melhoramento da imagem dos destinos, nos processos de controle de visitação - e outros aspectos da gestão - e na disponibilização categorizada de dados sobre a biodiversidade e a geodiversidade, contribuindo com a educação e interpretação ambiental. A usabilidade referente a tais processos de gestão varia, um exemplo de 
controle de visitação é através de uma opção de "check-in" com possibilidade de compartilhamento em mídias sociais. Um aspecto que fará parte de todas as propostas é a possibilidade de elaboração de aplicativos para dispositivos móveis, em especial para smartphones.

\section{Resultados e Discussões}

Primeiramente foi realizado um levantamento de dados e informações para identificar o cenário atual de cada Parque nos aspectos que influenciam a interpretação ambiental destes locais. Com base em um questionário aplicado por Baptista (2019), foi possível identificar - a partir de respostas dos respectivos gestores - quais as ferramentas interpretativas existentes em cada Parque. Posteriormente, com base em fontes bibliográficas, sites e lojas de aplicativos, foi realizado um levantamento dos principais tipos de tecnologia utilizados na interpretação ambiental em outros países.

Com as informações dos Parques brasileiros e os exemplos do exterior compilados, foi feito um diagnóstico e foram elaboradas propostas gerais e específicas. As propostas são de caráter sugestivo e buscam não fugir das realidades de cada UC.

Os Quadros 3, 4 e 5 (próximas páginas), cujo objetivo é apresentar os meios interpretativos utilizados em cada um dos Parques por estado, é composto de informações gerais (principais atrativos e atividades de uso público), dispostas no site do ICMBio e dados retirados do questionário elaborado e aplicado por Baptista (2019). Tais informações possibilitam a visualização do cenário atual dos Parques em relação à sua interpretação ambiental, no que diz respeito aos meios interpretativos tradicionais e os tecnológicos.

Como meios interpretativos tecnológicos, aqui, são considerados aqueles que utilizam ferramentas audiovisuais, bem como informações dispostas em plataformas virtuais, possibilitando o acesso dos visitantes através de seus smartphones ou computadores.

Os Parques Nacionais Marinho das llhas dos Currais e o de Guaricana foram os únicos em que os gestores não responderam ao questionário. Tais UCs são novas e não estão abertas oficialmente para visitação, nem possuem Plano de Manejo. 
Quadro 3: Meios interpretativos utilizados atualmente nos Parques Nacionais da região sul do Brasil - Paraná.

Frame 3: Interpretive media currently used in Brazilian Southern Region's National Parks - Paraná.

\begin{tabular}{|c|c|c|c|c|}
\hline $\begin{array}{l}\text { Parque } \\
\text { Nacional }\end{array}$ & Principais Atrativos & $\begin{array}{l}\text { Atividades de } \\
\text { Uso Público }\end{array}$ & $\begin{array}{c}\text { Meios } \\
\text { interpretativos } \\
\text { tradicionais }\end{array}$ & $\begin{array}{c}\text { Meios } \\
\text { interpretativos } \\
\text { tecnológicos }\end{array}$ \\
\hline Iguaçu & $\begin{array}{l}\text { Cataratas do Iguaçu; } \\
\text { Trilha do Poço Preto; } \\
\text { Trilha das Bananeiras; } \\
\text { Macuco Safari. }\end{array}$ & $\begin{array}{l}\text { Contemplação; } \\
\text { Rafting e } \\
\text { Arvorismo; } \\
\text { Trilha de } \\
\text { Bicicleta; } \\
\text { Avistamento de } \\
\text { fauna; } \\
\text { Passeio de } \\
\text { barco e caiaque } \\
\text { (Macuco } \\
\text { Ecoaventura). }\end{array}$ & $\begin{array}{l}\text { Condutores/Guias; } \\
\text { Exposições; } \\
\text { Folders; } \\
\text { Guias impressos; } \\
\text { Livros; } \\
\text { Painéis } \\
\text { interpretativos; } \\
\text { Placas indicativas } \\
\text { (sinalização); } \\
\text { Palestras; } \\
\text { Trilha (s) } \\
\text { interpretativas. }\end{array}$ & $\begin{array}{l}\text { Vídeos sobre a } \\
\text { UC; } \\
\text { Website; } \\
\text { Guias por áudio. }\end{array}$ \\
\hline Superagui & $\begin{array}{l}\text { Praia Deserta da Ilha do } \\
\text { Superagui; } \\
\text { Comunidade da Barra do } \\
\text { Superagui; } \\
\text { Trilha da Praia Deserta } \\
\text { Baía do rio das Peças, } \\
\text { Praia Deserta da Ilha das } \\
\text { Peças e Vila das Peças. } \\
\text { Ilhas Pinheiro e } \\
\text { Pinheirinho; } \\
\text { Roteiro Lagamar. }\end{array}$ & $\begin{array}{l}\text { Trilhas; } \\
\text { Contemplação; } \\
\text { Observação de } \\
\text { aves. }\end{array}$ & $\begin{array}{l}\text { Folders; } \\
\text { Livros; } \\
\text { Placas indicativas. }\end{array}$ & $\begin{array}{l}\text { Vídeos sobre a } \\
\text { UC. }\end{array}$ \\
\hline Ilha Grande & $\begin{array}{l}\text { Sítios históricos e } \\
\text { arqueológicos; } \\
\text { Lagos, lagoas, ilhas e } \\
\text { ilhotas. }\end{array}$ & $\begin{array}{l}\text { Contemplação; } \\
\text { Passeios de } \\
\text { caiaque; } \\
\text { Pedalinhos. }\end{array}$ & $\begin{array}{l}\text { Exposições; } \\
\text { Placas indicativas; } \\
\text { Palestras. }\end{array}$ & Não há. \\
\hline $\begin{array}{l}\text { Saint-Hilaire } \\
\text { Lange }\end{array}$ & $\begin{array}{l}\text { Beleza cênica (mata } \\
\text { atlântica); } \\
\text { Fauna. }\end{array}$ & $\begin{array}{l}\text { Trilhas; } \\
\text { Contemplação. }\end{array}$ & Folders. & Website. \\
\hline $\begin{array}{l}\text { Campos } \\
\text { Gerais }\end{array}$ & $\begin{array}{l}\text { Buraco do Padre; } \\
\text { Cachoeira da Mariquinha; } \\
\text { Cânion e Cachoeira do } \\
\text { Rio São Jorge; } \\
\text { Furnas Gêmeas; } \\
\text { Capão da Onça. }\end{array}$ & $\begin{array}{l}\text { Trilhas; } \\
\text { Passeios } \\
\text { guiados; } \\
\text { Contemplação; } \\
\text { Banhos de rio; } \\
\text { Rapel. }\end{array}$ & $\begin{array}{l}\text { Folders; } \\
\text { Palestras; } \\
\text { Cartilha/jogo. }\end{array}$ & Não há. \\
\hline $\begin{array}{l}\text { Ilhas dos } \\
\text { Currais }\end{array}$ & $\begin{array}{l}\text { Beleza cênica (bioma } \\
\text { marinho). }\end{array}$ & Contemplação. & Sem informações. & $\begin{array}{l}\text { Sem } \\
\text { informações. }\end{array}$ \\
\hline Guaricana & $\begin{array}{l}\text { Beleza cênica (mata } \\
\text { atlântica). }\end{array}$ & Contemplação. & Sem informações. & $\begin{array}{l}\text { Sem } \\
\text { informações. }\end{array}$ \\
\hline
\end{tabular}

Fonte: Elaborado pelos autores (2020) baseado Baptista (2019) e ICMBio (2018).

Source: Elaborated by the authors (2020) based on Baptista (2019) and ICMBio (2018). 
Quadro 4: Meios interpretativos utilizados atualmente nos Parques Nacionais da região sul do Brasil - Santa Catarina.

Frame 4: Interpretive media currently used in Brazilian Southern Region's National Parks - Santa Catarina.

\begin{tabular}{|c|c|c|c|c|}
\hline $\begin{array}{c}\text { Parque } \\
\text { Nacional }\end{array}$ & Principais Atrativos & $\begin{array}{c}\text { Atividades de Uso } \\
\text { Público }\end{array}$ & $\begin{array}{c}\text { Meios } \\
\text { interpretativos } \\
\text { tradicionais }\end{array}$ & $\begin{array}{c}\text { Meios } \\
\text { interpretativos } \\
\text { tecnológicos }\end{array}$ \\
\hline São Joaquim & $\begin{array}{l}\text { Paisagem (Morro da Igreja } \\
\text { com vista para a Pedra } \\
\text { Furada). }\end{array}$ & $\begin{array}{l}\text { Visitação ao Mirante } \\
\text { do Morro da lgreja; } \\
\text { Contemplação. }\end{array}$ & $\begin{array}{l}\text { Condutores/ Guias; } \\
\text { Exposições; } \\
\text { Folders; } \\
\text { Livros; } \\
\text { Placas indicativas } \\
\text { (sinalização). }\end{array}$ & $\begin{array}{l}\text { Website; } \\
\text { Guias por } \\
\text { áudio. }\end{array}$ \\
\hline $\begin{array}{l}\text { Serra do } \\
\text { Itajaí }\end{array}$ & $\begin{array}{l}\text { Beleza cênica (mata } \\
\text { atlântica); } \\
\text { Rios e cachoeiras. }\end{array}$ & $\begin{array}{l}\text { Contemplação; } \\
\text { Trilhas; } \\
\text { Banhos de rio; } \\
\text { Passeios de bicicleta. }\end{array}$ & $\begin{array}{l}\text { Trilha(s) } \\
\text { interpretativas. }\end{array}$ & Não há. \\
\hline Araucárias & $\begin{array}{l}\text { Beleza cênica (mata } \\
\text { atlântica); } \\
\text { Fauna. }\end{array}$ & $\begin{array}{l}\text { Contemplação; } \\
\text { Trilhas. }\end{array}$ & $\begin{array}{l}\text { Condutores/ Guias; } \\
\text { Placas indicativas } \\
\text { (sinalização); } \\
\text { Palestras. }\end{array}$ & $\begin{array}{l}\text { Vídeos sobre a } \\
\text { UC; } \\
\text { Website; } \\
\text { Página no } \\
\text { Facebook. }\end{array}$ \\
\hline Serra Geral & $\begin{array}{l}\text { Atributos cênicos, histórico- } \\
\text { culturais e de biodiversidade; } \\
\text { Conformação geográfica } \\
\text { peculiar; } \\
\text { Trilhas (Mirante do Fortaleza, } \\
\text { Pedra do Segredo e Borda } \\
\text { dos Cânions). }\end{array}$ & $\begin{array}{l}\text { Trilhas; } \\
\text { Contemplação. }\end{array}$ & $\begin{array}{l}\text { Condutores/ Guias; } \\
\text { Palestras }\end{array}$ & Website. \\
\hline
\end{tabular}

Fonte: Elaborado pelos autores (2020) baseado Baptista (2019) e ICMBio (2018).

Source: Elaborated by the authors (2020) based on Baptista (2019) and ICMBio (2018).

Quadro 5: Meios interpretativos utilizados atualmente nos Parques Nacionais da região sul do Brasil - Rio Grande do Sul.

Frame 5: Interpretive media currently used in Brazilian Southern Region's National Parks - Rio

Grande do Sul.

\begin{tabular}{|c|c|c|c|c|}
\hline $\begin{array}{l}\text { Parque } \\
\text { Nacional }\end{array}$ & Principais Atrativos & Atividades de Uso Público & $\begin{array}{c}\text { Meios } \\
\text { interpretativos } \\
\text { tradicionais }\end{array}$ & $\begin{array}{c}\text { Meios } \\
\text { interpretativos } \\
\text { tecnológicos }\end{array}$ \\
\hline $\begin{array}{l}\text { Aparados } \\
\text { da Serra }\end{array}$ & $\begin{array}{l}\text { Cânion Itaimbezinho; } \\
\text { Beleza cênica (mata } \\
\text { atlântica, floresta de } \\
\text { araucárias, campos e } \\
\text { penhascos); } \\
\text { Fauna endêmica (papagaio- } \\
\text { de-peito-roxo, jaguatirica, } \\
\text { guaxinim e leão-baio); } \\
\text { Trilhas (Vértice, Cotovelo e } \\
\text { Rio do Boi). }\end{array}$ & $\begin{array}{l}\text { Trilhas; } \\
\text { Bicicleta nas trilhas de planalto; } \\
\text { Banho de rio na trilha do Rio do } \\
\text { Boi; } \\
\text { Recreação em contato com a } \\
\text { natureza; } \\
\text { Visita à exposição; } \\
\text { Contemplação, fotografia ou arte; } \\
\text { Observação de Fauna; } \\
\text { Piquenique nas áreas permitidas. }\end{array}$ & $\begin{array}{l}\text { Condutores/Guias; } \\
\text { Palestras. }\end{array}$ & Website. \\
\hline $\begin{array}{l}\text { Lagoa do } \\
\text { Peixe }\end{array}$ & $\begin{array}{l}\text { Fauna (já foram } \\
\text { catalogadas } 275 \text { espécies } \\
\text { de aves); } \\
\text { Trilhas (Figueiras, Talha- } \\
\text { mar, Dunas, Flamingos); } \\
\text { Barra da Lagoa do Peixe. }\end{array}$ & $\begin{array}{l}\text { Trilhas; } \\
\text { Contemplação; } \\
\text { Observação de aves. }\end{array}$ & $\begin{array}{l}\text { Exposições; } \\
\text { Folders; } \\
\text { Painéis } \\
\text { interpretativos; } \\
\text { Placas indicativas. }\end{array}$ & Não há. \\
\hline
\end{tabular}

Fonte: Elaborado pelos autores (2020) baseado Baptista (2019) e ICMBio (2018).

Source: Elaborated by the authors (2020) based on Baptista (2019) and ICMBio (2018). 
São estes, portanto, os dados e informações necessários para a realização de análises que irão compor as propostas de aprimoramento dos meios interpretativos dos Parques Nacionais recortados para esta pesquisa. É importante ressaltar que tais propostas foram desenvolvidas de modo a adaptar as características dos modelos de ferramentas apresentados, configurando novos modelos mais próximos da realidade das UCs brasileiras. Cada Parque possui uma realidade e encontra-se em diferentes estágios com relação ao uso público. Fatores como acesso, a disposição dos atrativos e a própria data de criação e Planos de Manejo de cada UC constroem este cenário.

Em alguns casos a interpretação já ocorre de maneira satisfatória, mas não se descartam as possibilidades de aprimoramento. Em outros, a implementação da tecnologia pode surgir como fator complementar e/ou determinante na efetividade dos programas de interpretação.

De modo geral, nos Parques Nacionais da região sul, é possível observar a predominância dos meios interpretativos tradicionais, com poucas exceções, como websites, vídeos e guias por áudio. É importante destacar que o Parque Nacional das Araucárias, criado em 2005, possui o mesmo número de ferramentas tecnológicas que o Parque Nacional do Iguaçu, criado há mais de 60 anos. A utilização de websites, embora possua importância significativa no processo de interpretação, não faz parte da experiência dos visitantes no local. Esta ferramenta depende de um interesse, por parte destes visitantes, anterior ou posterior à visita. São essenciais, todavia, na divulgação e disponibilização de outros tipos de ferramentas tecnológicas.

A primeira proposta geral para os PARNAS da região sul do país está relacionada a um aspecto presente em todas as propostas individuais, as mídias sociais. Além da relevância das informações provenientes destes tipos de mídia, tratam-se de ferramentas prontas para o uso dos gestores, e na maioria das vezes gratuitas. Alguns exemplos de mídias sociais mais utilizadas no Brasil atualmente, e que podem contribuir com o fornecimento de informações relacionadas aos patrimônios das UCs para os visitantes são: Facebook, YouTube, Instagram, Twitter, Pinterest, entre outras.

Em seguida, e tendo como base os aplicativos sobre os Parques Nacionais Americanos, é sugerida a criação de um aplicativo para os Parques Nacionais Brasileiros, com uma proposta similar, que forneça informações gerais sobre todos os Parques, vinculados de alguma forma às mídias sociais. Uma proposta parecida foi criada pelo Ministério do Meio Ambiente em 2019, e está em uma fase "piloto". Mesmo diante da necessidade de um recorte geográfico para realização deste estudo, uma abordagem mais abrangente dos elementos aqui propostos também é pertinente.

Com as propostas descritas, e com as propostas específicas de ferramentas interpretativas a serem apresentadas, surge a necessidade de integração de todos estes recursos. Uma maneira de se fazer isso é através da criação de um website cuja página principal direciona os visitantes para plataformas em que os recursos tecnológicos de interpretação de cada UC estão disponíveis. Outra possibilidade conveniente para os visitantes é a incorporação de links de direcionamento no próprio site do ICMBio. 
No Quadro 6, são apresentadas as propostas específicas.

Quadro 6: Propostas específicas.

Frame 6: Specific proposals.

\begin{tabular}{|c|c|}
\hline Unidade de Conservação & Propostas \\
\hline $\begin{array}{l}\text { Parque Nacional do Iguaçu - } \\
\text { PR }\end{array}$ & $\begin{array}{l}\text { - Sala de cinema com tecnologia IMAX; } \\
\text { - Aplicativo para localização de atrativos, catalogação de espécies } \\
\text { da fauna e flora, segurança de modo geral, feedback dos } \\
\text { visitantes, entre outros aspectos. }\end{array}$ \\
\hline $\begin{array}{l}\text { Parque Nacional do Superagui } \\
- \text { PR }\end{array}$ & $\begin{array}{l}\text { - Aplicativo baseado em um mapa com pontos específicos de } \\
\text { interpretação, dividido em duas temáticas, uma natural e uma } \\
\text { cultural. } \\
\text { - Suporte para dispositivos móveis nas bicicletas do Parque. }\end{array}$ \\
\hline $\begin{array}{l}\text { Parque } \mathrm{Na} \\
-\mathrm{PR}\end{array}$ & $\begin{array}{l}\text { - Apli } \\
\text { - Apli }\end{array}$ \\
\hline $\begin{array}{l}\text { Parque Nacional de São } \\
\text { Joaquim - SC }\end{array}$ & - Esp \\
\hline $\begin{array}{l}\text { Parque Nacional de Aparados } \\
\text { da Serra - RS e Parque } \\
\text { Nacional da Serra Geral - } \\
\text { RS/SC }\end{array}$ & $\begin{array}{l}\text { de mídias impressas, } \\
\text { locais, com pequenas } \\
\text { do também no público }\end{array}$ \\
\hline $\begin{array}{l}\text { Parque Naci } \\
\text { Peixe - RS }\end{array}$ & $\begin{array}{l}\text { ção e banco de dados sobre aves que } \\
\text { no local; } \\
\text { rsonalizados. }\end{array}$ \\
\hline $\begin{array}{l}\text { Parque Nacional de Sair } \\
\text { Hilaire/Lange - PR }\end{array}$ & $\begin{array}{l}\text { - Incorporação de meios tradicionais como placas e painéis } \\
\text { interpretativos e ferramentas de sinalização nas trilhas e áreas de } \\
\text { visitação em geral; } \\
\text { - Implementação de códigos QR com conteúdo tematizado. }\end{array}$ \\
\hline $\begin{array}{l}\text { Parque Nacic } \\
\text { Gerais - PR }\end{array}$ & $\begin{array}{l}\text { o "O Trevo" (CARVAL } \\
\text { principais atrativos dc }\end{array}$ \\
\hline $\mathrm{Nac}$ & $\begin{array}{l}\text { - Apl } \\
\text { padr }\end{array}$ \\
\hline $\begin{array}{l}\text { Parque Nacional das Araucárias } \\
\text { - SC }\end{array}$ & de jogo sob \\
\hline $\begin{array}{l}\text { Parque Nacion } \\
\text { llhas dos Currai }\end{array}$ & \\
\hline $\begin{array}{l}\text { Parque } 1 \\
-\mathrm{PR}\end{array}$ & $\begin{array}{l}\text { lativo com base no compartill } \\
\text { rizadas. }\end{array}$ \\
\hline
\end{tabular}

Fonte: Elaborado pelos autores (2020).

Source: Elaborated by the authors (2020).

Tratam-se de ideias e sugestões que podem ser aplicadas ou utilizadas como modelo para criação de ferramentas semelhantes. A implementação das propostas feitas neste estudo não é impossível, já que as tecnologias descritas foram desenvolvidas e estão sendo utilizadas há anos em outros países, principalmente os aplicativos para dispositivos móveis. A sugestão da criação e gerenciamento de mídias sociais é direcionada a todos os Parques. 


\section{Considerações Finais}

Atualmente o uso de meios interpretativos tecnológicos nos Parques Nacionais da região sul do Brasil é pouco ocorrente e limitado se comparado a outras áreas naturais protegidas em outros países ao redor do mundo. Por este motivo, a aderência das pessoas a elementos tecnológicos e os benefícios e possibilidades que acompanham o uso de tecnologias em áreas naturais protegidas - em especial as tecnologias de Informação e comunicação para propósitos de interpretação ambiental - foram elementos analisados e levados em consideração na construção deste estudo.

Com exceção do Parque Nacional de Guaricana, todos os Parques da região sul estão abertos à visitação, o que varia são os números de visitantes, os tipos de estruturas disponíveis e a maneira como cada UC é gerida, facilitando ou não a visitação e as atividades que podem ser realizadas pelos visitantes.

Os meios interpretativos tecnológicos apresentam vantagens em relação aos meios interpretativos tradicionais, bem como algumas desvantagens a serem avaliadas. Atualmente, no Brasil, tais vantagens não vêm sendo bem aproveitadas quanto poderiam, ou como é possível observar em outros lugares do mundo. Cada UC possui atrativos únicos, cujos valores poderão ser potencializados através de uma estratégia de interpretação ambiental efetiva.

A primeira parte dos resultados apresentou um levantamento de informações que contemplou os meios interpretativos utilizados nos Parques Nacionais do Sul do Brasil e as ferramentas tecnológicas que estão sendo utilizadas para a interpretação ambiental no mundo atualmente. Foi possível constatar que os Parques brasileiros utilizam predominantemente ferramentas tradicionais, aproveitando muito pouco dos benefícios da utilização de novas tecnologias na interpretação ambiental. A partir desta constatação e da identificação de exemplos de sucesso do exterior, foi possível desenvolver um diagnóstico e propostas gerais e específicas para os Parques brasileiros.

O diagnóstico e as propostas desenvolvidas com base no levantamento de informações compuseram a segunda parte dos resultados. Concluiu-se que a mera tentativa de implementação de meios interpretativos similares aos que foram utilizados como exemplo resultaria em algumas frustrações, considerando o alto investimento necessário para elaboração e operacionalização de algumas das ferramentas em comparação com as demandas potenciais dos Parques brasileiros, entre outras variáveis. De todo modo, os benefícios da tecnologia não devem ser ignorados em programas efetivos e atuais de interpretação ambiental. Sendo assim, foram desenvolvidas propostas adaptadas às realidades de cada UC.

As propostas gerais tiveram como foco principal a integração de todas as propostas específicas através da criação de uma plataforma online como um website, ou o próprio endereço eletrônico do ICMBio, além da criação de um único aplicativo com informações sobre todas as UCs como no aplicativo National Parks dos Estados Unidos. Com relação às propostas específicas, os aplicativos móveis foram um elemento de destaque presentes em quase todas as propostas, devido ao custo relativamente baixo de desenvolvimento, à diversidade de oportunidades fornecidas por esta tecnologia e a pequena quantidade de impactos ambientais 
negativos decorrentes de seu uso. Além disso, é sugerida a gestão de páginas em mídias sociais para cada UC, pensando em benefícios anteriores e posteriores à visitação nesses locais.

\section{Agradecimentos}

Este trabalho é derivado do Programa Institucional de Bolsas de Iniciação Científica (PIBIC) da Universidade Estadual de Ponta Grossa (UEPG). Agradecemos o apoio da instituição de fomento desta pesquisa, o Conselho Nacional de Desenvolvimento Científico e Tecnológico (CNPq).

\section{Referências}

ANDRADE, T. Inovação Tecnológica e Meio Ambiente: A construção de novos enfoques. Ambiente e Sociedade. Campinas. v. 7, n. 1, jan./jun. 2004.

APPLESTORE. Leafsnap. Disponível em: $<$ https://itunes.apple.com/br/app/leafsnap/id430649829?mt=8>. Acesso em: 23 abr. 2018.

BAPTISTA, L. Tecnologia Móvel Enquanto Técnica Interpretativa em Unidades de Conservação: Relação com a experiência do visitante. Tese (Doutorado em Geografia) - Universidade Estadual de Ponta Grossa, Ponta Grossa, 2019.

BECK, L., CABLE, T. T. The Gifts of Interpretation. 3. ed. Urbana: Sagamore Publishing, 2011.

BENHOSSI, K. P., FACHIN, Z. O Meio Ambiente e o Embate entre a Preservação Ambiental e o Desenvolvimento Tecnológico: Uma Discussão de Direitos Fundamentais. Revista Jurídica Cesumar. v. 13, n. 1, p. 237-262, jan./jun. 2013.

BRASIL. Lei n. 9.985, de 18 de julho de 2000. Regulamenta o art. 225, § 10, incisos I, II, III e VII da Constituição Federal, institui o Sistema Nacional de Unidades de Conservação da Natureza e dá outras providências. Disponível em: $<$ http://www.planalto.gov.br/ccivil 03/LEIS/L9985.htm>. Acesso em: 23 abr. 2018.

CANDELLO, H. A Influência das Tecnologias de Informação e Comunicação (TICs) no Consumo do Patrimônio Cultural e Turístico por Visitantes e Residentes: Websites e mobile blogs. Obra Digital, São Paulo. n. 3, p.52-65, set. 2012.

FORIST, B. E., LITTLEJOHN, M., BAXTER, R., MACHLIS, G. E., GRAMANN, J. H. Visitor Use and Evaluation of Interpretive Media: A Report on Visitors to the National Park System. Social Science Program. Washington, 2003.

GOOGLEPLAY. Coral RKV. Disponível em: $<$ https://play.google.com/store/apps/details?id=org.hitlabnz.rekindlingvenus $>$. Acesso em: 23 abr. $2018 b$.

GOOGLEPLAY. Nature Guides. Disponível em: $<$ https://play.google.com/store/apps/details?id=com.enature.guides.npca2\&hl=en US >. Acesso em: 23 abr. 2018a. 
HAM, S. Environmental Interpretation: A practical guide for people with big ideas for small budgets. North American Press: Golden: Fulcrum Pub., 1992.

ICMBIO. PARNA Aparados da Serra. Disponível em: <http://www.icmbio.gov.br/parnaaparadosdaserra>. Acesso em: 23 out. 2017b.

PARNA

Araucárias.

Disponível

em:

$<$ http://www.icmbio.gov.br/portal/unidadesdeconservacao/biomas-

brasileiros/mataatlantica/unidades-de-conservacao-mata-atlantica/2199-parna-dasaraucarias >. Acesso em: 23 out. 2017j.

ICMBIO. PARNA Campos Gerais. Disponível em: $<$ http://www.icmbio.gov.br/portal/unidadesdeconservacao/biomas-

brasileiros/mataatlantica/unidades-de-conservacao-mata-atlantica/2207-parna-doscampos-gerais>. Acesso em: 23 out. 2017k.

ICMBIO. PARNA Iguaçu. Disponível em: <http://www.icmbio.gov.br/parnaiguacu>. Acesso em: 23 out. 2017a.

ICMBIO.

PARNA

Guaricana.

Disponível

em:

$<$ http://www.icmbio.gov.br/portal/ultimasnoticias/20-geral/8128-parque-nacional-deguaricana-faz-parceria-com-a-puc-pr>. Acesso em: 23 out. 2017m.

ICMBIO. PARNA Ilha Grande. Disponível em: $<$ http://www.icmbio.gov.br/portal/visitacao1/unidades-abertas-a-visitacao/4239parnailha-grande>. Acesso em: 23 out. $2017 \mathrm{~g}$.

ICMBIO. PARNA Lagoa do Peixe. Disponível em: $<$ http://www.icmbio.gov.br/portal/unidadesdeconservacao/biomasbrasileiros/marinho/ unidades-de-conservacao-marinho/2259 >. Acesso em: 23 out. 2017d.

ICMBIO. PARNA Marinho das Ilhas dos Currais. Disponível em: $<$ http://www.icmbio.gov.br/portal/parna-marinho-das-ilhas-dos-currais $>$. Acesso em: 23 out. 20171 .

ICMBIO. PARNA Saint Hilaire-Lange. Disponível em: $<$ http://www.icmbio.gov.br/portal/unidadesdeconservacao/biomas-

brasileiros/mataatlantica/unidades-de-conservacao-mata-atlantica/2193-parna-desaint-hilaire-lange>. Acesso em: 23 out. 2017h.

ICMBIO. PARNA São Joaquim. Disponível em: <http://www.icmbio.gov.br/parnasaojoaquim>. Acesso em: 23 out. 2017c.

ICMBIO. PARNA Serra do Itajaí. Disponível em:

$<$ http://www.icmbio.gov.br/portal/visitacao1/unidades-abertas-a-visitacao/731parquenacional-da-serra-do-itajai>. Acesso em: 23 out. $2017 \mathrm{i}$.

ICMBIO. PARNA Serra Geral. Disponível em:

$<$ http://www.icmbio.gov.br/portal/visitacao1/unidades-abertas-a-visitacao/730parquenacional-da-serra-geral.html>. Acesso em: 23 out. $2017 f$.

ICMBIO. PARNA Superagui. Disponível em: $<$ http://www.icmbio.gov.br/portal/visitacao1/unidades-abertas-a-visitacao/209parquenacional-do-superagui>. Acesso em: 23 out. 2017e. 
IUCN. Temas. Disponível em: <https://www.iucn.org/theme/protected-areas/about>. Acesso em: 23/10/2017.

KIRNER, C. ZORZAL, E. R. Aplicações Educacionais em Ambientes Colaborativos com Realidade Aumentada. Anais do XVI Simpósio Brasileiro de Informática na Educação. Juiz de Fora. UFJF, 2005.

MMA. Ministério do Meio Ambiente. Glossário. Disponível em: <http://www.mma.gov.br/areas-protegidas/cadastro-nacional-de-ucs/glossario>.

Acesso em: 23 out. 2017.

MOREIRA, J. C. Geoturismo e Interpretação Ambiental. Ponta Grossa: Editora UEPG. 2014.

MOSCARDO, G., WOODS, B., SALTZER, R. The Role of Interpretation in Wildlife Tourism. In: NEWSOME, D., DOWLING, R. K., MOORE, S. A. Wildlife Tourism: Impacts, Management and Planning. Australia. Common Ground. cap. 12. p. 231251. 2005.

NATIONALGEOGRAPHIC. IMAX Theater. Disponível em: $<$ https://explorethecanyon.com/imax-theater>. Acesso em: 23 abr. 2018a.

NATIONALGEOGRAPHIC. National Parks APP. Disponível em: $<$ https://www.nationalparks.org/connect/blog/national-geographic-national-park-app $>$. Acesso em: 23 abr. 2018b.

NG, Y. C. Y. FUNG, L. W; NEWSOME, D. Hong Kong Geopark: Uncovering the geology of a metropolis. In: DOWLING, R. NEWSOME, D. Global geotourism perspectives. Oxford: Goodfellow Publishers, 2010. cap. 13. p. 179-191.

NINTENDO. The Louvre Guide for Nintendo 3DS. Disponível em: <http://louvreguide.nintendo.com>. Acesso em: 10/09/2018.

RAMOS, C. M. Q., RODRIGUES, P. M. M., PERNA, F. Sistemas e Tecnologias de Informação no Sector Turístico. Revista Turismo e Desenvolvimento. São Paulo. n. 12, p. 21-32, 2009.

ROCHA, L. A. G., CRUZ, F. M., LEÃO, A. L. Aplicativo para Educação Ambiental. Anais do XI Fórum Ambiental da Alta Paulista, São Paulo. v. 11, n. 4, p. 261-273, 2015.

ROCHA, L. G. M. da, DRUMMOND, J. A., GANEM, R. S. Parques Nacionais Brasileiros: Problemas Fundiários e Alternativas para a sua Resolução. Revista de Sociologia e Política. v. 18, n. 36, p. 205-226, jun. 2010.

SNUC. Plano Estratégico Nacional de Áreas Protegidas. Disponível em: $<$ http://www.mma.gov.br/images/arquivos/areas protegidas/snuc/Livro\%20SNUC\%2 0 PNAP.pdf>. Acesso em: 23 out. 2017.

SONO. Dinopolis Theme Park. Disponível em: $<$ http://sono.es/en/proyectos/parquedinopolis-1-fase.html>. Acesso em: 23 abr. 2018.

STRATEGICCONTENT. Kew Gardens Official App. Disponível em: $<$ http://www.strategiccontent.co.uk/portfolio-items/kew-gardens-official-approyalbotanic-gardens-kew/>. Acesso em: 23 abr. 2018. 
TRIPADVISOR. Yellowstone IMAX Theater. Disponível em: $<$ https://www.tripadvisor.com.br/Attraction Review-g45399-d254115-Reviews-

Yellowstone IMAX Theatre-West Yellowstone Montana.html>. Acesso em: 23 abr. $2018 a$.

TRIPADVISOR. GPS Audio Driving Tour. Disponível em: $<$ https://www.tripadvisor.com/ShowTopic-g154909-i219-k5722740-

GPS audio driving tour for iPhone of Banff Lake Louise Jas-Alberta.html>.

Acesso em: 23 abr. 2018b.

VALE, T. F. do, ROBLES, R. A., MOREIRA, J. C. O Uso de Tecnologias em Museus e Centros de Visitantes: Estudo de Caso do Centro de Visitantes do Projeto Tamar em Fernando de Noronha - PE. Applied Tourism, v. 1, n. 1, p. 97-112. 2016.

ZOOAR. What is Zoo-AR? Disponível em: <http://zoo-ar.com>. Acesso em: 23 abr. 2018.

Eduardo Henrique Dias Carvalho: Universidade Estadual de Ponta Grossa, Ponta Grossa, PR, Brasil.

E-mail: eduardotur@outlook.com

Link para o currículo Lattes: http://lattes.cnpq.br/9575999489428240

Jasmine Cardozo Moreira: Universidade Estadual de Ponta Grossa, Ponta Grossa, PR, Brasil.

E-mail: jasminecardozo@gmail.com

Link para o currículo Lattes: http://lattes.cnpq.br/4244565636923524

Leandro Baptista: Universidade Estadual de Ponta Grossa, Ponta Grossa, PR, Brasil

E-mail: lbaptista@uepg.br

Link para o currículo Lattes: http://lattes.cnpq.br/4353198473576287

Data de submissão: 02 de abril de 2019

Data de recebimento de correções: 18 de dezembro de 2020

Data do aceite: 18 de dezembro de 2020

Avaliado anonimamente 